\title{
Presidential Address to the Society for Pediatric Research: a Foundation for Research
}

\author{
RALPH D. FEIGIN
}

Department of Pediatrics, Baylor College of Medicine and Texas Children's Hospital, Houston, Texas, USA

It is a privilege and honor to appear before you as President of the Society for Pediatric Research. I am grateful to all of you for allowing me to serve in this capacity.

The Society for Pediatric Research was founded in 1929. The purpose of the Society as stated in its constitution is, "To foster pediatric investigation and to provide an opportunity for younger investigators to present their work."

Many forces, both intrinsic and extrinsic to the pediatric academic community, have created potential impediments and challenges to fulfilling the stated purpose of the organization. As with most complex issues, it is relatively easy to identify the problems but far more difficult to develop clear solutions. Many of these problems have been reviewed both in the literature and by my predecessors during the course of presidential addresses during the previous two decades. This address will be devoted to a discussion of the rationale for and description of two new initiatives that were promulgated in response to these challenges.

The first of these initiatives chronologically has been the establishment of a Young Investigator Award. This annual award was established in part, as a response to the challenge to these societies represented by the increasing degrees of subspecialization within the pediatric community.

We have witnessed a tendency for investigators to desire stronger association with their partners in their own field of endeavor, whether their primary training is in pediatrics, medicine, surgery, or some other major field. We have observed with increasing frequency, discussion of the most appropriate forum for the presentation of an investigator's most meritorious work. Some have opted for a national meeting where investigators interested in a particular subspecialty discipline convene. Others have recognized a need in our present Society to be knowledgeable about scientific advances as they may relate to pediatric care in general and continue to submit their most meritorious work to our annual meeting where all individuals with an interest in pediatric research have an opportunity to listen to and comment upon the new information presented. I personally believe that the broader perspective in the long run would serve our discipline well.

The Young Investigator Award suggested by Dr. Pearay Ogra was designed to foster the recognition of young scholars who will embark on a career in investigative pediatrics. It also was designed to encourage presentation of the most meritorious work of these individuals first to a national assemblage of this type. The award provides the Society for Pediatric Research with an opportunity to honor and recognize these young scientists at the beginning of their pediatric careers. Eligibility for nomination for the award is limited to individuals in or following residency or fellowship training and those who have obtained their first faculty appointment within the calendar year of the submission of the nomination. Solicitation for the award was circulated during 1982.

A distinguished award committee (Table 1) consisting of senior investigators in various disciplines was assembled to judge the work of the nominees. Both the Awards Committee and the Council of the Society for Pediatric Research were overwhelmed by the magnitude and quality of the submitted manuscripts.

Immediately following this address, I will have the great pleasure of presenting to you the first winner of this award. Compe- tition was so keen, however, that the Awards Committee recommended giving recognition to five additional individuals whose work was deemed to be of extraordinary merit but who will not have an opportunity to be recognized as the awardee. This experience has reassured many of us that creative and innovative young people continue to enter the field of investigative pediatrics and that we should do whatever is deemed possible to see that their careers can be fostered in an era where funding has become increasingly difficult.

The second initiative has been undertaken in an attempt to improve the opportunities for funding for young investigators.

The success of the biomedical and behavioral research effort of this nation largely has been related to the partnership that has been established between the federal government and universities. This relationship has been so successful that we are prone to forget that contributions were made to improvements in child health prior to the advent of federal support.

At the meeting of the American Pediatric Society in 1929, the year that our Society was founded, 11 of the 31 papers were presented by what President Henry L. K. Shaw of the American Pediatric Society stated were younger men of promise, not yet members of that society (1). They were to become the first members of the Society for Pediatric Research. These presentations described among other things the indications for use and results of intravenous transfusion, studies of insensible water loss, studies of the prevention of staphylococcal infection in the newborn nursery, a study of the use of splenic puncture as a diagnostic measure in a number of diseases, a description of bone marrow aspiration for diagnostic purposes, and a paper describing the close relationship between acute nephritis and apparent streptococcal infection. All of these studies that have had a major impact upon our understanding of childhood disease and upon the care of children antedate by many years significant federal support of research efforts.

During World War I Congress recognized the value of research; its first appropriation for medical research was $\$ 285,000$ a year for 3 years and came in 1918. The money was allocated for mission-oriented research, specifically, for the study of a cure for venereal diseases. The cause for which the money was allocated clearly had merit. Despite the application of these funds for mission-oriented research 65 years ago, we have not conquered venereal diseases, in fact, they are on the increase. The lesson obtained from this brief historical insight is that mission-oriented research frequently does not have the immediate payoff that government, industry, and the general public suspect.

The National Institutes of Health were established in 1930; by current standards, extramural funding was minimal.

The advent of World War II spurred an intensive effort in biological research; by 1944 federal funds for research and biology reached $\$ 600$ million per year. Following the second World War the greatest biomedical research enterprise in the world was fueled by federal funding for faculty investigation.

Since 1970 federal funding for research measured in constant dollars has increased minimally (Fig. 1) and future prospects for any increases, as may be gleaned from the administration's budget proposals for 1984, appear to be non-existent (2). The number of 
new and competing grants awarded by NIH in 1982 was 917 below the number awarded in 1979. The number of new and competing renewal grants that may be funded under the proposed 1984 NIH budget is projected to be about 3700; 1327 less than 1982 (3). Since the number of grants eligible for award and recommended for approval increased substantially during the past 4 years, the percentage of grants that receive awards has declined substantially (Fig. 2).

Table 1. Young investigator award committee

Pearay L. Ogra, M.D., Buffalo, New York, Coordinator

Carol J. Baker, M.D., Houston, Texas

Merton Bernfield, M.D., Stanford, California

Richard J. Grand, M.D., Boston, Massachusetts

Richard E. Hillman, M.D., St. Louis, Missouri

Alexander R. Lawton, M.D., Nashville, Tennessee
Despite these constraints, NIH is doing exceedingly well in that it has fared better than many of the social service programs that are of great importance to child health care. The long-term trend is clear, however. The years of NIH's explosive growth appear to be behind us. Biomedical research-as important as it is to society-must be prepared to line up with a variety of other interests to do pitched battle for the public dollar.

Approximately 2 years ago, in our attempts to achieve stability in federal research funding, we accepted the premise that we could settle for the support for a given number of research grants and a given number of trainees. Five thousand new and competing research grants and 10,000 research trainees were the strategies chosen. While intending to establish a floor for research funding, we found ourselves with an agreed-to-ceiling and since we are in a period of national retrenchment, we have been called upon to operate below that ceiling. The remedy for this dilemma lies in political action. Our societies have been politically active and at

TRENDS IN NIH EXTRAMURAL AWARDS, FISCAL YEARS 1972-82

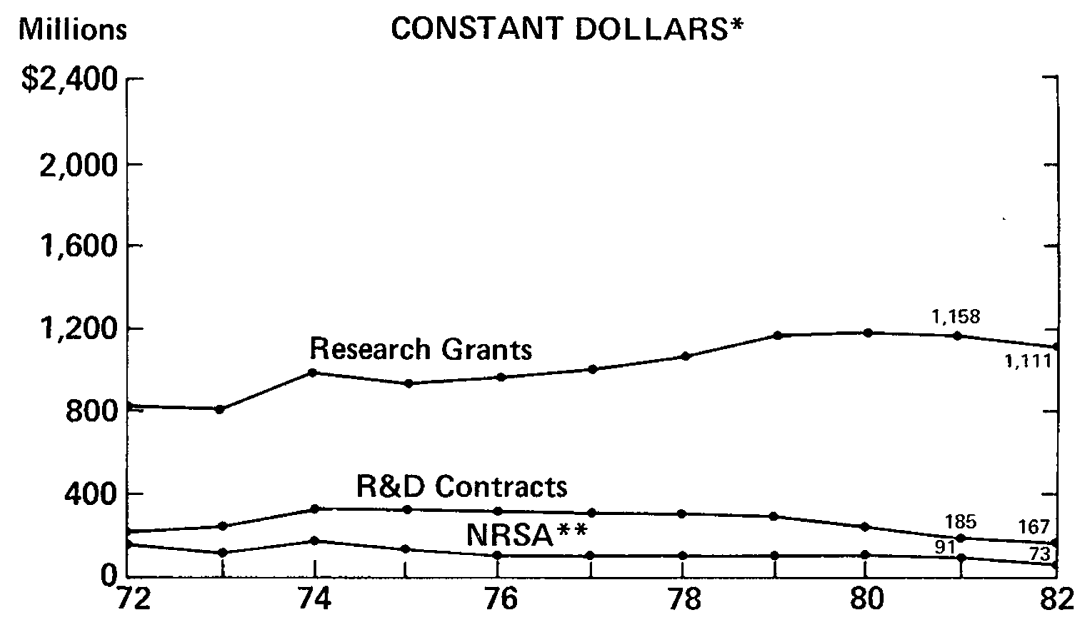

Note: Excludes To. *Based on biomedical R\&D price deflator FY 1972=100. ** Includes pre-NRSA training.

Source: NIH, DRG, Statistics and Analysis Branch

Fig. 1. Trends in NIH extramural awards. Fiscal years 1972-1982, reported in constant dollars.

\section{NUMBER OF NIH COMPETING RESEARCH PROJECT APPLICATIONS REVIEWED, RECOMMENDED FOR APPROVAL BY COUNCIL AND AWARDED, FISCAL YEARS 1972-82}

Number(Thous.)

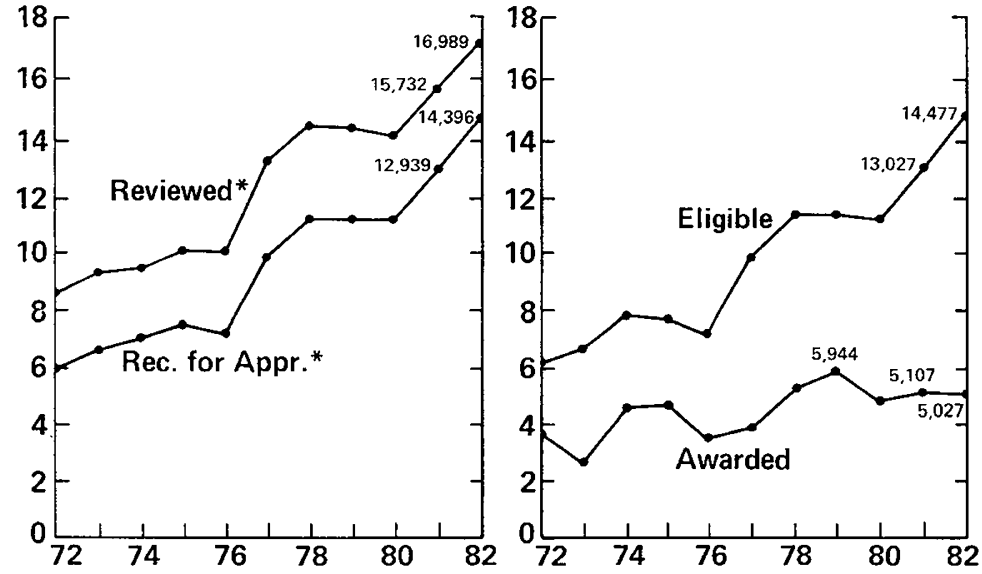

Note: Data based on NIH standard procedures. * Reporting year Source: NIH, DRG, statistics and analysis branch

Fig. 2. Number of NIH competing research project applications reviewed, recommended for approval by council and awarded for fiscal years $1972-$ 1982. 
least, in part, the success achieved in obtaining more funds than President Reagan suggested for the 1983 budget can be attributed to these actions.

The decreased availability of public funds has prompted institutions and individual investigators to look elsewhere for resources. Simultaneously, extraordinary developments made possible by recombinant DNA techniques have prompted both industrialists and medical researchers to move with speed and determination to search for useful and profitable products.

The interest of industry in reaching appropriate arrangements with universities have been summarized most succinctly by Dr. Theodore Cooper as follows: (4) (1) To gain patentable ideas or entities; (2) to have access to patients for clinical trials; (3) to have publications of clinical studies which are valuable for promotional aids; (4) to attract personnel to the company or staff as consultants; and (5) to have the prestige of association with a university with its implied reliability and quality.

These are the factors that have motivated the large contracts such as Monsanto granting $\$ 23$ million to Harvard for cancer research; Exxon granting $\$ 8$ million to MIT for combustion research; and the Hoechst Corporation granting $\$ 50$ million over a period of 10 years to the Massachusetts General Hospital to establish a molecular biology department. All of these corporate funds are directed towards the support of basic research programs and virtually all of the funding corporations have the right of first refusal on patents developed from this research.

Problems of academic-industrial interaction have caused concerns and debate at major universities about potential or real conflicts of interest between those fundamental principles which define the purposes of academic institutions and of industry. The National Commission on Research, founded in 1978, recently reviewed the state of research and innovation in the United States and considered in detail the variety of needs and philosophies guiding the actions of universities, industry, and the government. The Commission concluded that university-industrial relationships are beneficial and should be encouraged.

The need for continued political action to ensure maintenance of federally funded research is clear. The need for a continued dialogue to ensure the integrity of individual investigators and institutions in their interaction with industry is equally apparent. These needs are reasonably well understood. But, there is an additional need expressed in the purpose of our Society that concerns me more than the others and that is the need for a program for the support of young investigators. It is this latter need towards which I have worked during the past 2 years and it is to address this need that the second new initiative of our Society has been directed.

Almost two years ago I initiated discussions with a number of corporate executives and attorneys concerning the possibility of establishing a foundation for pediatric research. The purposes of such a foundation would be to create an endowment. The interest would be used to fund small research proposals submitted by pediatric investigators immediately following their formal period of training and during their first 5 years on the faculty of a pediatric department.

Grants would be awarded on the basis of merit utilizing the same independent peer review grant process that has proven so successful in the distribution of research funds from the National Institutes of Health. It is hoped that these funds might provide seed monies for pilot projects that ultimately might be funded by NIH or other organizations. The corporate sector would be assured of being positively identified with those research projects that had been reviewed and that were most likely to result in major advances in the care of infants and children in the future.

Many of the concerns and potential objections to universityindustrial relationships include: $(l)$ a skewing of research priorities inappropriately encouraging over-emphasis on applied research; (2) interference with choice by faculty members of the scientific questions that they might wish to pursue; (3) compromise in the ability of scientists to retain their objectivity in evaluating the scientific merit of various advances; (4) promotion of inappropriate secrecy among scientists, thereby hampering the free flow of information; and (5) restriction of publication of potentially profit making ideas would be avoided by such a plan. On the other hand, it would be unrealistic to expect major corporations to provide the millions of dollars that they have expended in specific contractual relationships with a number of universities if they did not have the right of first refusal for potentially profitable concepts. Thus, I proposed that we solicit small contributions ranging from $\$ 5,000$ to $\$ 10,000$ from a large number of corporations nationally, in recognition of the fact that some of those who pay the cost under this plan cannot avoid having much of the resulting benefit flow to others. In addition, contributions of this size hopefully would not interfere with the proprietary interest exhibited by most universities toward major corporate entities located in their own communities. Contributions to the Foundation in the amount solicited would provide the corporate sector with a mechanism to fund non-targeted research, but research that had been carefully reviewed for merit.

What has been accomplished to date? On April 28, 1982 the Pediatric Research Foundation was incorporated as a non-profit corporation. Articles of Incorporation and By-Laws were filed and tax-exempt status for the Foundation was granted by the Internal Revenue Service on September 3, 1982. We all owe an eternal debt of gratitude to Mr. Robert Hopson and Mr. Darrell Morrow of the Vinson Elkins Law Firm who devoted their considerable time and talents to this endeavor at no cost to the Society for Pediatric Research and its members.

What type of foundation is the Pediatric Research Foundation? Let me briefly review for you in a simplistic manner selected pertinent regulations with regard to the various forms of foundations so that you can understand more readily reasons for choosing to establish the type of foundation that was selected.

One type of foundation is a private foundation. The advantages of establishing a private foundation would be the ability to appoint only members of the Society for Pediatric Research as trustees. Individual donors, however, would be restricted in the amount that they might contribute to a private foundation. Private foundations are, in turn, restricted in their ability to solicit funds from other private foundations. In this regard, it should be noted that many major corporations have created private foundations which they use as a mechanism for making grants. If we had established a private foundation, we would not have been permitted to solicit funds from some of these corporate entities. Private foundations also are subject to a $2 \%$ tax on their net investment income and must make distributions on a yearly basis in an amount defined by the tax code. During the initial time required to develop the Pediatric Research Foundation, we deemed it important to avoid the requirement that a given percentage of the total foundation's assets be divested. Despite the potential advantage offered by virtue of having only society members as trustees of the foundation, the establishment of a private foundation would have had major significant disadvantages.

There are three categories of public charities. The first are organizations which as a result of common law are viewed as being responsive to the public need. Churches, hospitals, and schools are included in this category.

A second category of public charities are those that are frequently termed "Public Foundations." These foundations are independent of any other organization and are managed by public trustees. More than one-third of the total support for these foundations must come from members of the general public. No more than one-third of their support can come from selected groups viewed as substantial or major contributors. Substantial contributors are defined by law as individuals or entities who have contributed an amount that exceeds the greater of $\$ 5,000$ or $2 \%$ of the total support received by the organization. The public foundation also must satisfy a test that essentially requires that fundraising activities be carried out yearly and that it, at no time, live off the income generated by an endowment fund. These regulations made it undesirable to file for incorporation and tax-exempt status as a public foundation. Fortunately, another legal recourse existed.

It was possible to file for exemption as a public charity by 
establishing the Foundation as a supporting organization. Supporting organizations are organizations operated for the benefit of an already designated public charity-in this case-the Society for Pediatric Research. A supporting organization, by law, must have both public and private trustees. There are, however, no restrictions on the size of donations. There is no obligation to raise funds yearly. There is no obligation to distribute any particular proportion of income or principal in any given year. There is no specific ceiling on the total dollars or proportion of total dollar contributions that may be contributed to the foundation by a single donor. For all of these reasons, establishing the Foundation for Pediatric Research as a support foundation was the optimal choice.

The Pediatric Research Foundation is a support foundation whose sole purpose is to provide funds to its sole beneficiary, the Society for Pediatric Research. It is the Society for Pediatric Research that will make the grant awards utilizing funds provided to it by the Foundation. Although the Pediatric Research Foundation is legally distinct and separate from the Society for Pediatric Research, it is, in fact, completely controlled by the Society for Pediatric Research.

Essential elements contained in the articles of incorporation and by-laws of the Foundation for Pediatric Research pertinent to the governance of the Foundation include the following five items.

(1) The Board of Trustees is divided into Society trustees and public trustees as required by law. At all times, however, at least $60 \%$ of the trustees must be Society trustees.

(2) Society trustees appointed to serve as Foundation trustees may be active, senior or emeritus members of the Society for Pediatric Research.

(3) The two initial public trustees were selected by the officers of your Society for Pediatric Research. The number of Society and public trustees may be increased but in the event that more than $40 \%$ of the trustees are public trustees, only $40 \%$ of the votes may be cast by public trustees. Since the Society trustees, appointed by the Council of the Society for Pediatric Research, always have the majority vote $(60 \%)$ and since the trustees of the Foundation select any new public trustees, the Society, in effect, has the right and capability to appoint all public trustees in perpetuity.

(4) Any public trustee may be removed from office with or without cause by affirmative majority vote of all of the members of the Society for Pediatric Research.

(5) The Board of Trustees of the Foundation also may establish a Board of Advisory Trustees composed of members of the community who, because of their expertise and familiarity with the activities in which the Foundation is engaged, are in the judgment of the Board of Trustees of the Foundation qualified to advise with respect to the Foundation's activities. These advisory trustees have no vote.

An Advisory Board of Trustees composed of senior corporate executives, broadly representative of the business community, has been established. These individuals have pledged to aid the Foundation in its fund-raising activities and have agreed to provide advice and counsel with regard to investments of the assets of the Foundation. I am personally deeply indebted to these business leaders for their willingness to help us with this new endeavor.

The Council of the Society for Pediatric Research shall determine, by whatever mechanism they may agree upon, those individuals who may receive grant support, the size of the grants to be awarded, and the precise mechanisms for the distribution of income made available to it by the Foundation.

The share of academic research funds acquired from industry will never replace government funding. There are, in fact, no tax mechanisms that effectively encourage corporate boards of directors or venture capitalists to invest in non-targeted research. To assure the effectiveness of our approach, however, we have not merely sought industrial largesse. Through the help of a number of legislators, several bills will be introduced in the current session of the Congress that if passed, will make contributions of the type that we seek more attractive to the corporate community.

W. I. B. Beveridge, in the Art of Scientific Investigation, noted that: "The majority of discoveries in biology and medicine have been come upon unexpectedly, or at least had an element of chance in them, especially the most important and revolutionary ones (5). One of the best illustrations of such discovery originating from hypotheses is provided by the story of the voyage of Christopher Columbus. It has many of the features of a classic discovery in science. He was obsessed with an idea; the idea was by no means original. He met with great difficulty in getting someone to provide the money to enable him to test his idea as well as in the actual carrying out of the experimental voyage. When he finally succeeded, he did not find the expected new route but instead found a whole new world."

It is my hope that with your help solicitation of funds will be successful. The Foundation may then, in turn, provide the funds to enable young investigators similarly obsessed with ideas to test those ideas and carry out their experiments so that they, too, not only will have an opportunity to prove or disprove their hypotheses but may, per chance, improve the lives of the children whom we all serve by finding a whole new world.

\section{REFERENCES AND NOTES}

1. Faber, H. K. and McIntosh, R.: History of the American Pediatric Society 1987 1965. (McGraw Hill Book Company, New York).

2. Source Document. Extramural Trends, NIH-FY 1972-1981. Statistics and Analysis Branch, Division of Research Grants.

3. Personal Communication: Dr. James Sidbury.

4. Cooper, T.: Changing Patterns of Biomedical Research Funding: A View from Industry. Presented at AFCR Public Policy Symposium, 39th Annual Meeting. Washington, D.C., May 9, 1982.

5. Beveridge, W. I. B.: The Art of Scientific Investigation. Chapters 3 and 4. (W. W. Norton Publishing Company, New York). 